\title{
Designing a Construct of Chimeric Multi-Epitopes Protein for Contraceptive Vaccine in Mice: An Immu- noinformatics and In Silico Study
}

\author{
Behnam Mortazavi ${ }^{1}$ Q, Najaf Allahyari Fard ${ }^{2 *}$ Q Farid Heidari $^{1}$ Q, Ali Asghar Karkhaneh ${ }^{2}$ Q, Mohammad Ali Eslamizade ${ }^{1}$
}

1 Department of Animal Biotechnology, Faculty of Agriculture Biotechnology, National Institute of Genetic Engineering and Biotechnology (NIGEB), Tehran, Iran.

2 Department of Systems Biotechnology, Faculty of Industrial and Environmental Biotechnology, National Institute of Genetic Engineering and Biotechnology (NIGEB), Tehran, Iran.

\begin{tabular}{|c|c|}
\hline $\begin{array}{l}\text { Use your device to scan } \\
\text { and read the article online }\end{array}$ & ditation Mortazavi B, Allahyari Fard N, Heidari F, Karkhaneh AA, Eslamizade MA. Designing a Construct of Chimeric \\
\hline 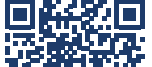 & $\begin{array}{l}\text { Multi-Epitopes Protein for Contraceptive Vaccine in Mice: An Immunoinformatics and In Silico Study. Research in Molecular } \\
\text { Medicine. 2020; } 8(2): 71-82 . \text { https://doi.org/10.32598/rmm.8.2.894.1 }\end{array}$ \\
\hline 口ifichas & d cl" https://doi.org/10.32598/rmm.8.2.894.1 \\
\hline
\end{tabular}

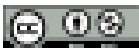

Article Type:

Research Article

Article info:

Received: 22 Feb 2020

Revised: 19 Apr 2020

Accepted: 25 Apr 2020

Keywords:

IZUMO1, SACA3, PH-

20, Contraceptive vaccine,

Chimeric protein

\begin{abstract}
A B S T RA C T
Background: Contraceptive Vaccines (CVs) can be used as a valuable and alternative method for the prevention of gestation in humans and animals. These vaccines can have several targets, such as superficial sperm proteins. Vaccines based on sperm antigens are quite efficacious to create a contraceptive effect. However, multi-epitope vaccines are more effective in stimulating the immune system and producing more antibodies to reduce the infertility rate.

Materials and Methods: This study aimed to design and evaluate a chimeric fusion protein containing IZUMO, SACA3, and PH-20 epitopes. IZUMO1, SACA3, and PH-20 were assessed, and appropriate regions were selected using various bioinformatics tools, including IEDB, I-TASSER, ProtParam, Asa-View, and Chimera software. Protein epitopes were selected based on various characters, including specificity, solvent accessibility, their weight and length, antigenic intensity, and topology. Epitopes with high antigenic potential were selected and joined together by linkers. The designed fusion protein was simulated using Molecular Dynamic, GROMACS 5, and Chimera 1.14 software.

Results: The results demonstrated that all antigenic plots and availability of epitopes in the new construct remained constant. The spermatic antigens were combined using rigid linkers as a new construct and showed a stable formation with proper solvent accessibility validated by ProSA-web and PROCHECK. Also, comparing the new structure with its original one did not show any structural change.

Conclusion: Based on bioinformatics results, the fusion protein that consists of three spermatic antigens has productive potential to stimulate the immune system and capable of producing more antibodies in circulation and reliable infertility.
\end{abstract}

* Corresponding Author:

Najaf Allahyari Fard, PhD.

Address: Department of Systems Biotechnology, Faculty of Industrial and Environmental Biotechnology, National Institute of Genetic Engineering and Biotechnology (NIGEB), Tehran, Iran

Phone: +98 (912) 09124494760

E-mail: allahyar@nigeb.ac.ir 


\section{Introduction}

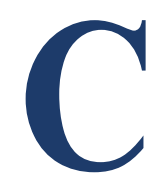

ontraceptive Vaccines (CV) may provide an alternative approach to control unintended pregnancies and animal populations [1]. Recent research indicates that $9 \%$ to $36 \%$ of couples are infertile because of sperm autoimmunity $[2,3]$. Sperm antibody is detected in $8 \%$ to $21 \%$ of the infertile male partners $[3,4]$ and $6 \%$ to $23 \%$ of the female partners [2, 4-6]. Several CVs have been studied and introduced to inhibit gamete production (such as LHRH, FSH, and GnRH) [7, 8], sperm and oocyte antigens [9], and gamete outcome (LIF and hCG) [10-12]. The blood-testis barrier separates spermatogonial and immune cells. Sperm antigens releasing to blood lead to autoimmune response against spermatogonial cells [13]. Antigen-antibody complex clots sperms and limits their motility [14]. Immune response to spermatogonial cells results in infertility in both males and females [15].

Various antigens are used to produce contraceptive vaccines. IZUMO1, SACA3, and PH-20 antigens are essential for sperm function and oocyte fertilization [16-18]. Utilizing the full length of these proteins individually with reduced fertility goals can partially interfere with fertility [19-21]. IZUMO1 is a sperm cell surface protein that plays a role in penetrating sperm by interacting with JUNO, which is located on oocyte, and binding of these two proteins together is necessary for oocyte fertilization [22, 23]. Also, studies that focus on gene knockout proves that IZUMO protein has an effective role in sperm penetration [24]. Recently, several variations in the JUNO gene have been found which can be related to female infertility and disrupting sperm-egg binding [25].
SACA3 is a sperm surface membrane protein that is involved in adhesion and fusion of sperm during fertilization. This protein binds to $\mathrm{N}$-acetylglucosamine, which is located on the surface of the oocyte $[18,26]$. Reverse transcription-polymerase chain reaction and immunohistochemistry determine the SACA3 expression in the oocyte, corpora lutea, and ovarian follicles [27]. This protein has a critical role in the early phase of embryo development in many species $[18,19,28]$.

Hyaluronidase PH-20 protein is encoded by the Spam1 gene and contributes to sperm-oocyte adhesion. This protein is an anchored-GPI protein, which digests hyaluronic acid of cumulus cells to facilitate sperm penetrating oocyte $[29,30]$. PH-20 is a multi-functional protein, besides hyaluronidase property, it is a receptor for HA-induced cell signaling and binding to the zona pellucida [31-36].

A series of monoclonal antibodies have been produced using hybridoma and recombinant DNA technology, which interferes in the fertility process in various species of animals [9, 37-40]. The notable ones are SP-10 (sperm protein 10) [41], FA-1 (fertilization antigen 1), FA-2 [42], lactate dehydrogenase (LDH)-C4 [43, 44], ZP3 [45], YLP12 peptide [46], SAMP32 [47, 48], and SAMP14 [49]. The identification of appropriate epitopes with high antigenic and immunogenic potential is the first step in designing a recombinant protein. This procedure can be accomplished by in silico methods and bioinformatics tools. Studies indicate that a combination of epitopes can enhance immunogenicity and create powerful reversible infertility [50].

In a similar study, it was observed that immunization with complete uPA protein might have serious side effects

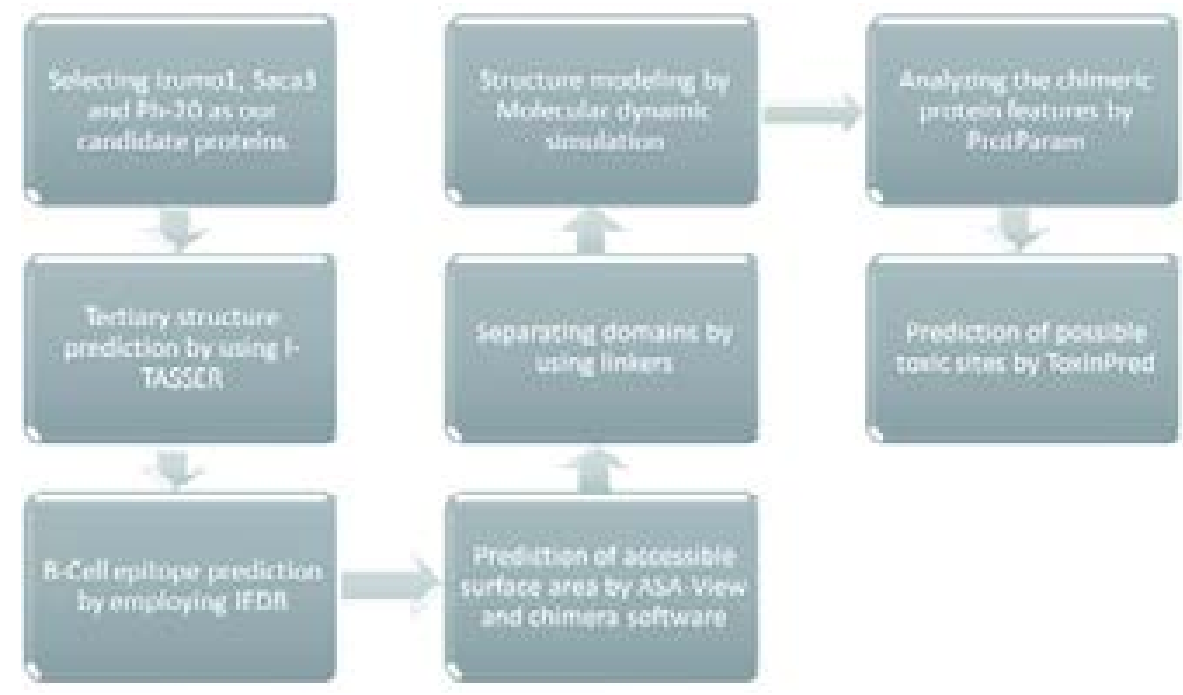

Figure 1. The schematic image of the research stages 
and induce immune tolerance at higher doses while using B-cell epitopes reduce adverse effects and enhance the immune specificity $[51,52]$. The purpose of this study was to design a new vaccine, consisting of three spermatic proteins (IZUMO1, SACA3, and PH-20), which can induce $\mathrm{B}$ cells and results in contraception by the immune response. Multi-epitope vaccines have more potential for stimulating the immune system and producing more antibodies to reduce the infertility rate. This study was done and designed for mice, but the results, process, and methods can be used for other animals, too.

\section{Materials and Methods}

The research had several stages, including protein selection, tertiary structure prediction of proteins, epitope prediction, solvent accessibility prediction, protein engineering, structure modeling and simulation, physicochemical parameters, and evaluating toxic fragments. Figure 1 displays the research process steps.

\section{Protein selection}

Initially, the selection of proteins for $\mathrm{CV}$ production was carried out using UniProt (www.uniprot.org) and Protein Atlas (www.proteinatlas.org) databases. Then IZUMO1 (UniProt: Q9D9J7 and Gene ID: 73456), SACA3 (UniProt: Q9D9X8 and Gene ID: 75622) and PH-20 (UniProt: P48794 and Gene ID: 20690) were selected as desirable candidates. All sequences were obtained from NCBI (www.ncbi.nlm.nih.gov/protein), and the isoforms were analyzed by the BLASTP program and the UniProt database.

\section{Tertiary structure prediction of proteins}

Due to the lack of full 3D structures of IZUMO1 and PH-20, the whole structures were simulated using ITASSER (Iterative Threading ASSEmbly Refinement) [53], which is a hierarchical approach to protein structure and function prediction. I-TASSER server is an integrated platform for automated protein structure and function prediction based on the sequence-structurefunction paradigm. The server is free for academic users and available at https://zhanglab.ccmb.med.umich. edu/I-TASSER/. The 5B5K and 2PE4 PDB codes were considered as templates for IZUMO1 and $\mathrm{PH}-20$ simulation, respectively. The structure of the SACA3 with 4yf2 PDB code is fully available in the PDB (https://www. rcsb.org/) database.

\section{Epitope prediction}

In this stage, the 3D structure and exposed regions of the proteins are considered. High antigenic areas were determined by employing The Immune Epitope Database (IEDB) [54] (https://www.iedb.org/). IEDB contains an extensive collection of experimentally measured immune epitopes and a suite of tools for predicting and analyzing epitopes. IEDB has antibody, and T cell epitopes for infectious diseases, allergens, autoimmune diseases, and transplant/alloantigens studied in humans, non-human primates, mice, and other animal species. It has two sections: prediction and analysis tools. Prediction tools predict the outcome of experiments, such as MHC class I or class II binding, MHC class I processing and immunogenicity, and for predicting linear and discontinuous (conformational) B cell epitopes. The epitope prediction tools are valuable resources for vaccine researchers when experimentally measured epitopes are not available in IEDB. To assign antigenic potency, epitope regions were analyzed based on sequence (prediction of linear epitopes from protein sequence) and structure in "'B cell tool".

The antigenicity plots of the extracellular region were obtained according to the seven sequences based methods which are listed in the IEDB software [55-60]. Structural B-cell epitopes were predicted using Ellipro (minimum score of 0.5 and a maximum distance of $6 \dot{A}$ ) [61]. Similarity analysis of three epitopes was done using Clustal Omega, which is a multiple sequence alignment program that uses seeded guide trees and HMM profileprofile techniques to generate alignments between three or more DNA or protein sequences.

\section{Solvent accessibility prediction}

The accessible surface area or solvent accessibility of epitopes are predicted by ASA-View [62] (http://ccbb. jnu.ac.in/shandar/servers/asaview/) both quantitatively and qualitatively. This server provides a graphical representation of the solvent accessibility of amino acid residues in proteins with known structures. We also used Chimera 1.13rc software to analyze the available surface of epitopes schematically. Chimera is a program for the interactive visualization and analysis of molecular structures and related data, including density maps, sequence alignments, docking results, and trajectories.

\section{Protein engineering}

Non-helical linkers can create multi-functional chimeric proteins, which consist of modules from various proteins. 
These linkers create structural rigidity and isolation of linkers from the attached epitopes. Two types of rigid linkers were used for protein engineering to link the epitopes and form a fixed and non-interference structure of fusion protein $[63,64]$. Codon optimization and in silico cloning were carried out using EMBOSS and GenSmart servers in Escherichia coli $\mathrm{K}-12$ as a prokaryotic host [65].

\section{Structure modeling and simulation}

The fragment structures were combined and modeled by MODELLER 11. It is used for homology or comparative modeling of three-dimensional protein structures. MODELLER implements comparative protein structure modeling by satisfaction of spatial restraints. It can perform many additional tasks, including de novo modeling of loops in protein structures, optimization of various models of protein structure with respect to a flexibly defined objective function, multiple alignments of protein sequences and or structures, clustering, searching of sequence databases, comparison of protein structures, etc. To achieve the final composition of the fusion protein, we performed a Molecular Dynamics (MD) simulation with GROMACS [66].

It is one of the most widely used open-source and free software codes in chemistry and biology used primarily for dynamical simulations of biomolecules. It was developed by Groningen University. GROMACS can work in the operating system Linux. The primary ability of GROMACS is to perform MD simulation and minimization energy [67]. It provides a rich set of calculation types, preparation, and analytic tools. GROMACS 5 was used in the operating system Linux, and the force field was Gromos 54A7 with 50 ns. For simulating the system, sodium $(\mathrm{Na}+)$ and chloride $(\mathrm{Cl}-)$ ions were used to neutralize, SPC model for filling water, with pressure 1 bar, at the temperature of 300 Kelvin, and neutral $\mathrm{pH}$ set.

Root-Mean-Square Deviation (RMSD) and RootMean-Square Fluctuation (RMSF) diagrams of simulated protein were obtained from studying the physical movements of atoms and molecules [68]. To recognize the errors in the generated model, coordinates were supplied by uploading 3D structure in PDB format into ProSA-web [69] (https://prosa.services.came.sbg.ac.at/ prosa.php) and PROCHECK server [70] (https://servicesn.mbi.ucla.edu/PROCHECK/), which are frequently employed in protein structure validation.

\section{Physiochemical parameters}

The protein features such as instability index, molecular weight, aliphatic index, theoretical isoelectric point (pI), half-life in Escherichia coli and mammals, the total number of positive and negative residues, and grand average hydropathy were analyzed in ProtParam [71] (https://web.expasy.org/protparam/).

\section{Evaluating toxic fragments}

The existence of potential toxic sites was predicted by ToxinPred [72] (https://webs.iiitd.edu.in/raghava/ toxinpred/protein.php) server. ToxinPred is an in silico method, developed to predict and design toxic/non-toxic peptides. The main dataset used in this method consists of 1805 toxic peptides.

\section{Antigenicity and allergenicity assessment of the} chimeric protein

IEDB evaluated the antigenicity of the chimeric protein, and the structural database of allergenic proteins (SDAP) and AlgPred assessed the allergenicity of the chimeric protein. SDAP is a server that integrates the database of allergenic proteins with various computational tools and assists structural biology studies related to allergens [73]. AlgPred allows the prediction of allergens based on the similarity of known epitope with any region of the protein [74].

\section{Results}

Following the selection of IZUMO1, SACA3, and PH-20, the isoform study by BLASTP demonstrated some similarities in their domains, such as the Ig-like C2 domain in IZUMO1, glycoside hydrolase family 22 in SACA3, and glycoside hydrolase family 56 in PH-20.

The locations of the extracellular region of proteins considered for epitope selection are aa 22-319 in IZUMO1, aa 91-221 in SACA3, and all sequences in PH-20. The IEDB results revealed that some regions of proteins have high antigenicity potential in terms of sequence and structure. In sequence-based methods, each epitope above the threshold is considered. Also, Table 1 lists 8 linear B-cell epitopes represented by analyzing the 3D structure. Table 2 presents the selected epitopes based on the score of sequence and structure methods.

The available position of the IZUMO1 structure is from aa 22-257, while the location of the selected epitope is aa $249-291$, so the whole structure by 5B5K pattern code 
Table 1. Predicted linear B-cell epitopes for the 3D structure of proteins

\begin{tabular}{|c|c|c|c|c|c|c|}
\hline Protein & Chain & $\begin{array}{c}\text { Start } \\
\text { Position }\end{array}$ & $\begin{array}{l}\text { End } \\
\text { Position }\end{array}$ & Peptide & Number of Residues & Score \\
\hline \multirow{3}{*}{ IZUMO } & A & 249 & 256 & DVTVLPPK & 8 & 0.844 \\
\hline & A & 219 & 230 & TKSMVGPEDAGN & 12 & 0.757 \\
\hline & A & 238 & 241 & INQG & 4 & 0.614 \\
\hline \multirow{3}{*}{ SACA3 } & A & 88 & 129 & $\begin{array}{l}\text { LASSKAKVFSRCELAKEMHDFGLDGYRGYN- } \\
\text { LADWVCLAYYTS }\end{array}$ & 42 & 0.679 \\
\hline & B & 115 & 128 & QGRDLSDWVDGCDF & 14 & 0.733 \\
\hline & C & 115 & 126 & QGRDLSDWVDGC & 12 & 0.832 \\
\hline \multirow{3}{*}{$\mathrm{PH}-20$} & A & 265 & 273 & KKDLKSNRQ & 9 & 0.688 \\
\hline & & & & & & \\
\hline & A & 226 & 240 & NKFODPFYDGQCPAV & 15 & 0.654 \\
\hline
\end{tabular}

Table 2. Selected epitopes based on top scores in sequences and structure methods

\begin{tabular}{cccccc}
\hline Protein & Chain & $\begin{array}{c}\text { Start } \\
\text { Position }\end{array}$ & $\begin{array}{c}\text { End } \\
\text { Position }\end{array}$ & $\begin{array}{c}\text { Number of } \\
\text { Residues }\end{array}$ & Epitope Sequence \\
\hline IZUMO1 & A & 249 & 291 & 43 & DVTVLPPKHSEENQPPNIITQEEHETPVHVTPQTPPGQEPESE \\
SACA3 & A & 119 & 148 & 30 & ADWVCLAYYTSGFNTNAVDHEADGSTNNGI \\
PH-20 & A & 220 & 247 & 28 & FPDCYNNKFQDPKYDGQCPAVEKKRNDN \\
\hline
\end{tabular}

was simulated. To simulate the entire PH-20 structure, we used 2PE4 PDB code with a 38\% identity between them.

The first used rigid linker for joining IZUMO1 and SACA3 epitopes was AEAAAKA, and the second linker was APAPAP for joining SACA 3 and PH-20 epitopes. Rigid linkers can make firm gaps between protein domains, and the distance between them can be controlled by changing their length. For the AEAAAKA linker, we used a single specific repeat, but three AP repeats for the second linker.
Since the protein weight is less than $20 \mathrm{kDa}$ and may not have proper antigenicity and stability, epitopes regions were extended in two sides to reach the ideal weight and size. Table 3 presents the final sequence, which consists of 270 amino acids (epitopes and linkers in the fusion protein).

Analyzing the similarity of three epitopes using Clustal Omega revealed that epitopes have no similarity by themselves. The obtained results by ProtParam showed that protein molecular weight was $30.465 \mathrm{kDa}$. The theoretical

Table 3. The position of epitopes and linkers in the fusion protein

\begin{tabular}{|c|c|c|c|c|}
\hline Construct & $\begin{array}{l}\text { Start Position in The } \\
\text { Main Protein }\end{array}$ & $\begin{array}{l}\text { End Position in The } \\
\text { Main Protein }\end{array}$ & $\begin{array}{l}\text { Start Position in The } \\
\text { Fusion Protein }\end{array}$ & $\begin{array}{l}\text { End Position in The } \\
\text { Fusion Protein }\end{array}$ \\
\hline Epitope region 1 (IZUMO1) & 210 & 300 & 1 & 91 \\
\hline Linker 1 & \multicolumn{2}{|c|}{ AEAAAKA } & 92 & 98 \\
\hline Epitope region 2 (SACA3) & 100 & 184 & 99 & 183 \\
\hline Linker 2 & \multicolumn{2}{|c|}{ APAPAP } & 184 & 189 \\
\hline Epitope region 3 (PH-20) & 195 & 275 & 190 & 270 \\
\hline
\end{tabular}




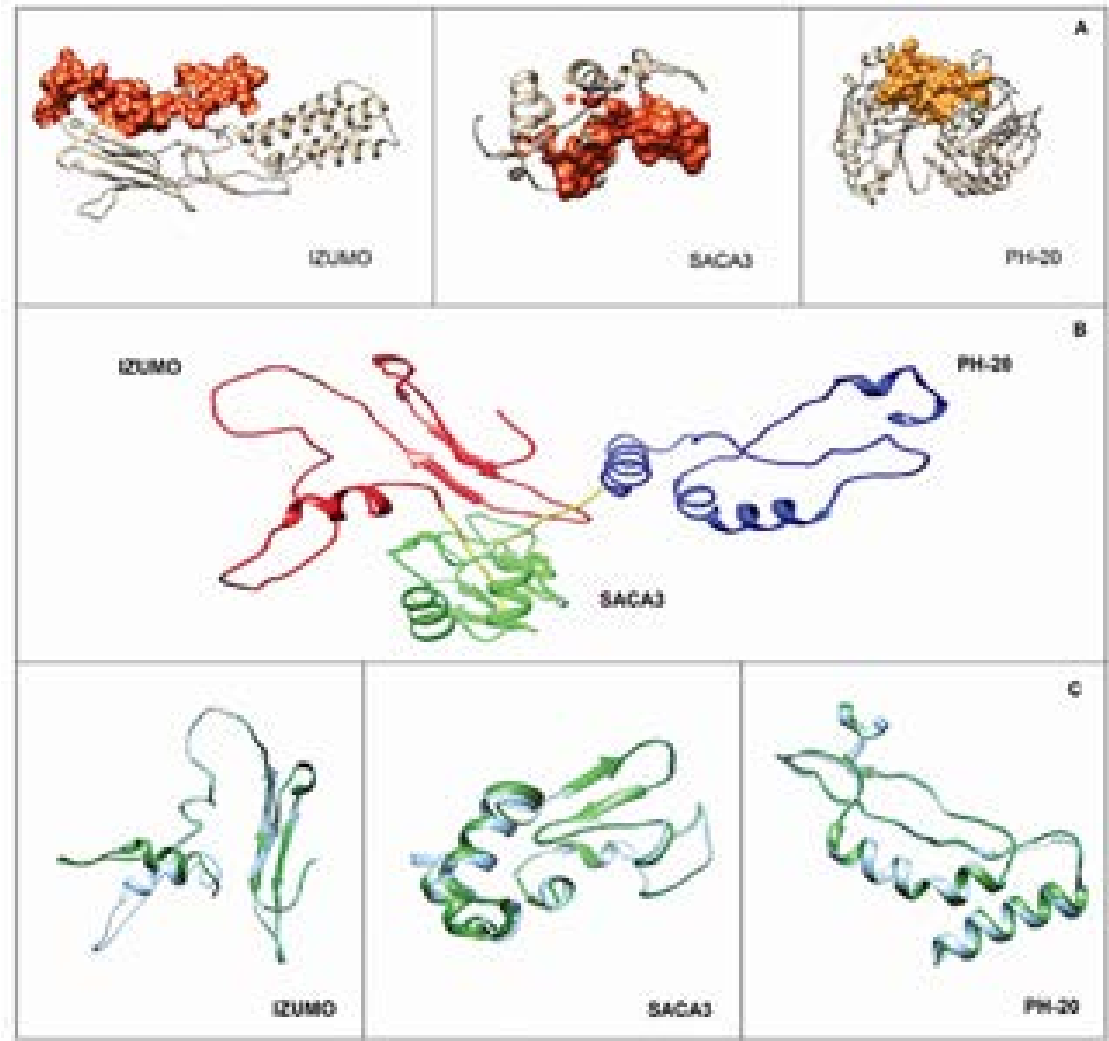

Figure 2. Surface accessibility and analyzing the new construct

A. Localization of potential B-cell epitopes on the protein structure in red; B. The final composition of the fusion protein, using the molecular dynamic output. The fusion protein consists of three epitopes, which colored in red (IZUMO), green (SACA3), blue (PH-20), and yellow (linkers); C. Examining the structural changes in the fusion protein.

isoelectric point (pI) was 5.93. The total number of Asp and Glu amino acids was 34, and Arg and Lys were 29, so fusion protein has a negative charge. The biocomputed half-life in mammals was 20 hours and in E. coli greater than 10 hours. Based on the instability index, Expasy's ProtParam classified the optimized chimeric protein as stable (instability index: 39.93). Aliphatic index of chimeric protein was 68.33 . The extinction coefficient of optimized chimeric protein at $280 \mathrm{~nm}$ was $50225 \mathrm{M}-1 \mathrm{~cm}-1$.

The solvent accessibility scores of epitope regions obtained by Asa-View in IZUMO1, SACA3, and PH-20 were $0.54,0.37$, and 0.33 , respectively. After obtaining PH-20 and IZUMO1 structure from I-TASSER, and by possessing the SACA3 structure, we used Chimera software to determine the available epitope surface regions, as shown in Figure 2. The findings showed that epitope regions are located at the surface of the fusion protein (Figure 2a). The final structure of the fusion protein obtained using MD is shown in Figure 2b. To examine the structural changes in the fusion protein, we aligned the structures derived from MD with previous structures obtained by I-
TASSER and PDB web server. The SACA3 and PH-20 epitope regions are perfectly matched, but there is a slight change in IZUMO1 epitope region alignment that could not have a significant impact on the main structure (Figure 2c). Next, a Ramachandran plot analysis of the model was obtained from PROCHECK. Analysis of the simulated fusion protein revealed that $98.7 \%$ of the residues are placed in the favored region and $1.3 \%$ in the disallowed part of the Ramachandran plot (Figure 3a). The z-score of the model simulated by MD for overall model quality was -4.99 , and within the range of scores typically found in native proteins of similar size (Figure $3 b$ ).

The results of IEDB to examine the remaining constant of antigenicity plots in fusion protein demonstrated that all antigenicity plots in all seven methods did not change. Figure 4 shows two examples of diagrams for BepiPred linear epitope prediction and Chou and Fasman beta-turn prediction.

The RMSD diagram declared that fusion protein reaches a stable structure after $50 \mathrm{~ns}$, and the RMSF diagram 

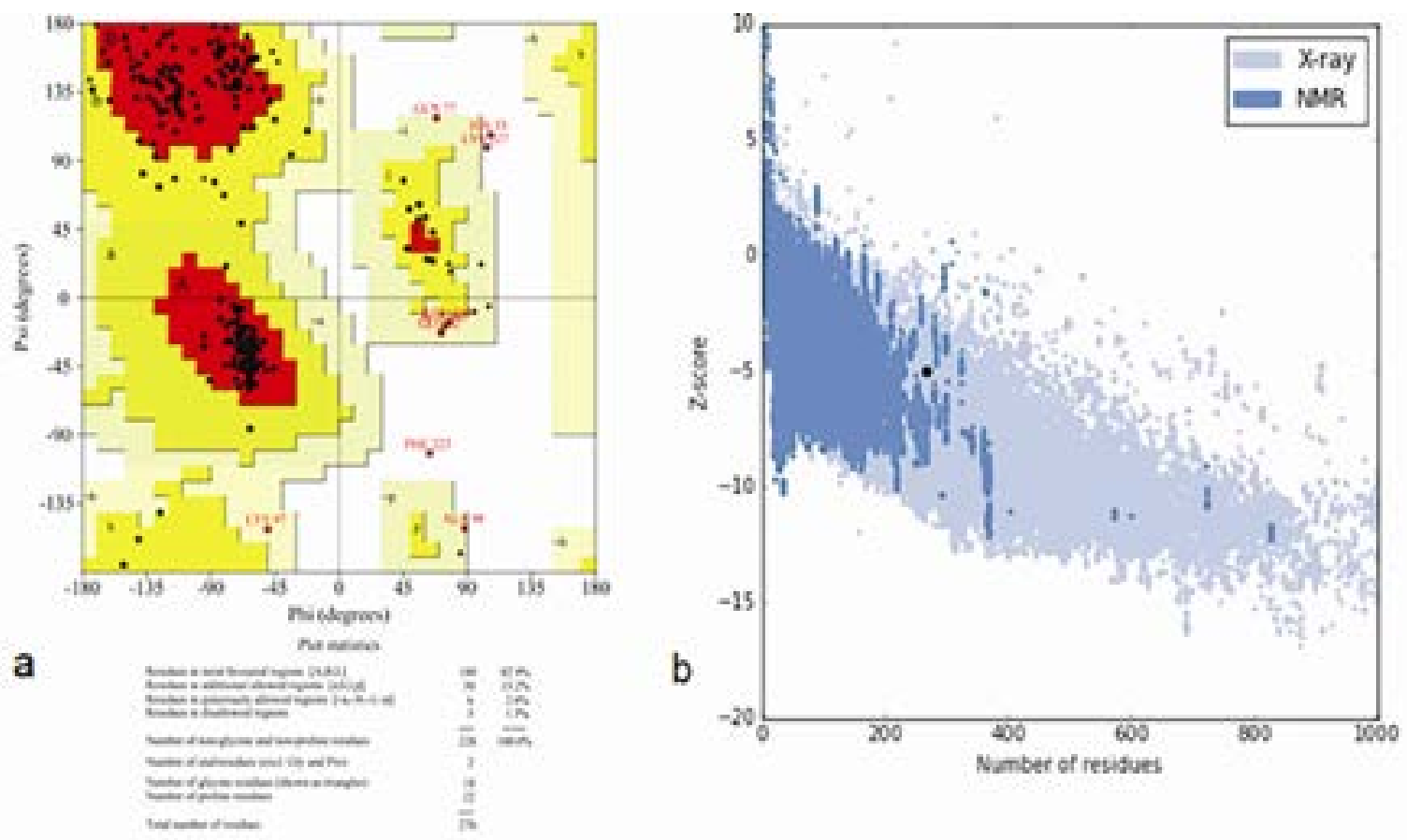

binm

Figure 3. Ramachandran plots and z-score analysis

A. Ramachandran plot analysis for the fusion protein: 189 residues in most favored regions $(82.9 \%), 30$ residues in the additional allowed regions (13.2\%), 6 residues in the generously allowed regions (2.6\%), 3 residues in the disallowed regions $(1.3 \%)$. B. Z-score plot for the tertiary structure of constructing: The z-score checks the input structure within the range of scores generally found in native proteins from different sources (X-ray, NMR) with a similar size (69)
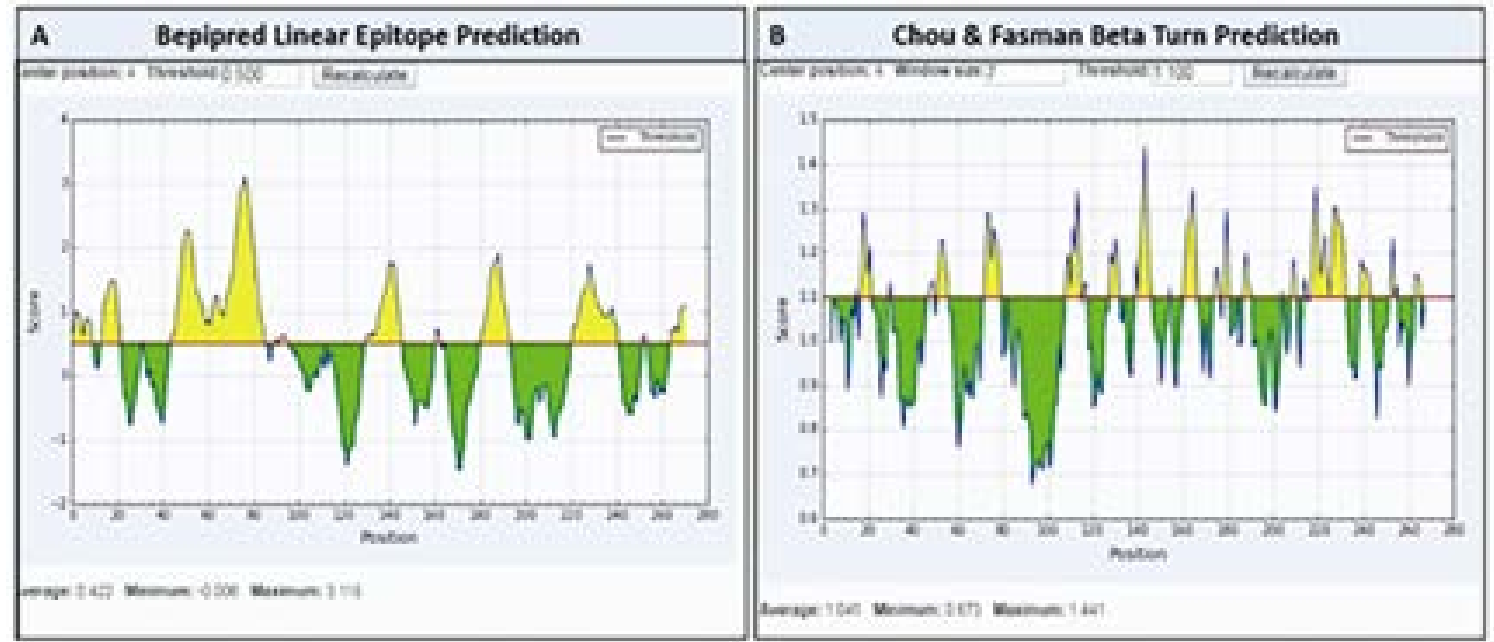

bimm

Figure 4. Two examples of antigenicity plots of the fusion protein obtained by IEDB: Yellow peaks exhibit high antigenic areas, and green peaks denote low antigenic regions of the fusion protein.

A. BepiPred linear epitope prediction (threshold 0.500). The peaks above the threshold are recognized by antibodies.

B. Chou and Fasman beta-turn prediction (threshold 1.100).

The regions above the threshold have beta turns in the fusion protein. 

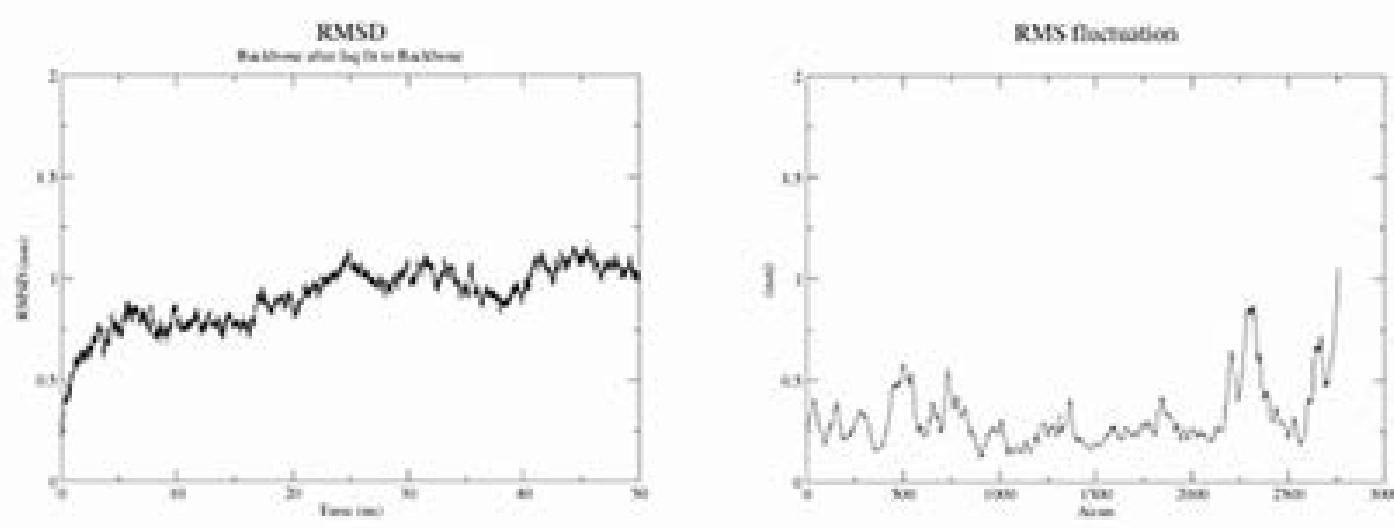

Figure 5. Root-mean-square deviation (RMSD) and root-mean-square fluctuation (RMSF) diagrams

shows the activity of atoms and their movements in a biological environment in which they are acceptable in all epitopes (Figure 5). RMSD can be employed to recognize large changes in protein structure as compared with the starting point. In molecular dynamics, we are interested in how structures and parts of structures change over time as compared with the starting point. RMSF is a calculation of individual residue flexibility, or how much a particular residue moves during a simulation [73].

ToxinPred data results of the chimeric protein did not show significant toxicity. Only two segments (LFPDCYNNKF and FPDCYNNKFQ), which is related to $\mathrm{PH}-20$ protein with $0.1 \mathrm{E}$-value, indicated mild toxicity, which is not noticeable. Allergenicity assessment of the chimeric protein did not reveal any similarity and crossreactivity with the known allergens.

\section{Discussion}

Several proteins have been introduced as Contraceptive Vaccine (CV) candidates so far. These vaccines must not have side effects. Hence, sperm-specific molecules are the best choice for antisperm CV development. Similar to the other vaccine production procedures, the progress in $\mathrm{CV}$ development has been lingering owing to the variability of immune response and assorted antibody titers after vaccination $[75,76]$. However, we suggested that multi-epitope vaccines can enhance the efficacy of the variability of the response.

Also, due to the variable duration of antibodies circulation and its effect on fertility, new explorations have focused on enhancing the immunogenicity of the $\mathrm{CV}$ based on sperm-specific proteins [77]. The reason for the selection of three proteins is to reach more potent and prolonged immunogenicity [78].
Various antigens are used to produce contraceptive vaccines. In this regard, IZUMO1, SACA3, and PH-20 antigens that are essential proteins for sperm function and oocyte fertilization can be the promising candidates. Utilizing the full length or partial length of these proteins individually with reduced fertility goals can partly interfere with fertility [19-21]. Since IZUMO1, SACA3, and PH-20 play a critical role in sperm function, deactivation of these proteins might have a significant impact on fertility [50]. The combination of various peptides involved in different steps of the fertilization, such as sperm-oocyte binding and penetrating sperm into the oocyte, can enhance the efficacy compared to using these peptides alone [79]. Up to now, no one has reported $100 \%$ infertility after immunization with sperm antigens. So the combination of these epitopes may enhance the rate of infertility in animal models.

Similar observations have also been reported with the combination of IZUMO and ZP3 epitopes to elicit a robust immune response compared with using IZUMO or ZP3 alone, thereby immunization of female mice with a recombinant fusion protein versus its individual fragments resulted in higher antibody titer [80].

RMSD plots indicate that the chimeric protein is stable during the simulation. MD simulation showed that the predicted structure is stable, and the selected rigid linkers can separate the domains of designed fusion constructs effectively. Toxicity and allergenicity assessment of the chimeric protein is significant and noticeable. The various components of the vaccines (i.e., protein or polysaccharide antigen, adjuvants, and excipients) should be assessed for their direct effects, and be safe without similarity or cross-reactivity with the known allergens and toxins [81]. 
Our results also demonstrated that this fusion protein has a suitable half-life in mammals like mice, which can stimulate the immune system for a longer time and provide a stronger response. The in silico data revealed that the fusion protein structure has not changed compared with the original structure and makes us use it instead of one protein to enhance the immunogenicity. Since the previous experiments that used surface sperm antigens for infertility did not yield reliable results, so the combination of these proteins is a good option, which requires more clinical trials.

\section{Conclusion}

The results of the present study can help us to select an appropriate fusion vaccine for contraception. In summary, all computational analyses showed that the fusion vaccine has structural stability and suitable distance between domains. Also, the flexibility and the solvent accessibility of the construct has an adequate antigen presentation for the immune system. The combination of epitopes as a fusion vaccine can be employed instead of using specific spermatic protein for $\mathrm{CV}$ production. Besides, it is expected to have high antibody titer and prolonged sterilization by injecting into animal models.

\section{Ethical Considerations}

\section{Compliance with ethical guidelines}

Compliance with ethical guideline: All ethical principles were considered in this article.

\section{Funding}

Funding: This research did not receive any specific grant from funding agencies in the public, commercial, or notfor-profit sectors.

\section{Authors contribution's}

All authors contributed in preparing this article.

\section{Conflict of interest}

The authors declared no conflict of interests.

\section{Acknowledgements}

The authors wish to thank the National Institute of Genetic Engineering and Biotechnology (NIGEB) for their kind cooperation.

\section{References}

[1] Henshaw SK. Unintended pregnancy in the United States. Fam Plan Perspect. 1998; 30(1):24-46. [DOI:10.2307/2991522] [PMID]

[2] Menge AC, Medley NE, Mangione CM, Dietrich JW. The incidence and influence of antisperm antibodies in infertile human couples on sperm-cervical mucus interactions and subsequent fertility. Fertil Steril. 1982; 38(4):439-46. [DOI:10.1016/S0015-0282(16)46578-7]

[3] Collins J, Burrows E, Yeo J, YoungLai E. Frequency and predictive value of antisperm antibodies among infertile couples. Hum Reprod. 1993; 8(4):592-8. [DOI:10.1093/oxfordjournals.humrep.a138102] [PMID]

[4] Menge AC, Beitner O. Interrelationships among semen characteristics, antisperm antibodies, and cervical mucus penetration assays in infertile human couples. Fertil Steril. 1989; 51(3):486-92. [DOI:10.1016/S0015-0282(16)60559-9]

[5] Brazdova A, Senechal H, Peltre G, Poncet P. Immune aspects of female infertility. Int J Fertil Steril. 2016; 10(1):1.

[6] Barlow DH. Antisperm antibodies in infertility. Br Med J (Clin Res Ed). 1988; 296(6618):310. [DOI:10.1136/ bmj.296.6618.310] [PMID] [PMCID]

[7] Ferro VA, Stimson WH. Anti-gonadotropin releasing hormone vaccines and their potential use in the treatment of hormone-responsive cancers. BioDrugs. 1999; 12(1):1-12. [DOI:10.2165/00063030-199912010-00001] [PMID]

[8] Manetti G, Honig S. Update on male hormonal contraception: is the vasectomy in jeopardy? Int J Impot Res. 2010 22(3):159. [DOI:10.1038/ijir.2010.2] [PMID]

[9] Naz RK, Sacco A, Singh O, Pal R, Talwar GP. Development of contraceptive vaccines for humans using antigens derived from gametes (spermatozoa and zona pellucida) and hormones (human chorionic gonadotrophin): current status. Hum Reprod Update. 1995; 1(1):1-18. [DOI:10.1093/ humupd/1.1.1] [PMID]

[10] Lemons AR, Naz RK. Birth control vaccine targeting leukemia inhibitory factor. Mol Reprod Dev. 2012; 79(2):97-106. [DOI:10.1002/mrd.22002] [PMID] [PMCID]

[11] Lemons AR, Naz RK. Contraceptive vaccines targeting factors involved in establishment of pregnancy. Am J Reprod Immunol. 2011; 66(1):13-25. [DOI:10.1111/j.16000897.2011.01001.x] [PMID] [PMCID]

[12] Naz RK. Contraceptive vaccines. Drugs. 2005; 65(5):593603. [DOI:10.2165/00003495-200565050-00002] [PMID]

[13] Cheng CY, Mruk DD. The blood-testis barrier and its implications for male contraception. Pharmacol Rev. 2012; 64(1):16-64. [DOI:10.1124/pr.110.002790] [PMID] [PMCID]

[14] Esteves SC, Schneider DT, Verza Jr S. Influence of antisperm antibodies in the semen on intracytoplasmic sperm injection outcome. Int Braz J Urol . 2007; 33(6):795-802. [DOI:10.1590/ S1677-55382007000600007] [PMID]

[15] Ohl DA, Naz RK. Infertility due to antisperm antibodies. Urology. 1995; 46(4):591-602. [DOI:10.1016/S0090-4295(99)80282-9]

[16] Hardy CM, Clydesdale G, Mobbs KJ, Pekin J, Lloyd ML, Sweet C, et al. Assessment of contraceptive vaccines based 
on recombinant mouse sperm protein PH20. Reproduction. 2004; 127(3):325-34. [DOI:10.1530/rep.1.00016] [PMID]

[17] Ellerman DA, Pei J, Gupta S, Snell WJ, Myles D, Primakoff P. Izumo is part of a multiprotein family whose members form large complexes on mammalian sperm. Mol Reprod Dev. 2009; 76(12):1188-99. [DOI:10.1002/mrd.21092] [PMID] [PMCID]

[18] Mandal A, Klotz KL, Shetty J, Jayes FL, Wolkowicz MJ, Bolling LC, et al. SLLP1, a unique, intra-acrosomal, nonbacteriolytic, c lysozyme-like protein of human spermatozoa. Biol Reprod. 2003; 68(5):1525-37. [DOI:10.1095/biolreprod.102.010108] [PMID]

[19] Chiu W, Erikson E, Sole C, Shelling A, Chamley L. SPRASA, a novel sperm protein involved in immune-mediated infertility. Hum Reprod. 2004; 19(2):243-9. [DOI:10.1093/ humrep/deh050] [PMID]

[20] Primakoff P, Lathrop W, Woolman L, Cowan A, Myles D. Fully effective contraception in male and female guinea pigs immunized with the sperm protein PH-20. Nature. 1988; 335(6190):543. [DOI:10.1038/335543a0] [PMID]

[21] Wang DG, Huang TH, Xie QD, An G. Investigation of recombinant mouse sperm protein izumo as a potential immunocontraceptive antigen. Am J Reprod Immunol. 2008; 59(3):225-34. [DOI:10.1111/j.1600-0897.2007.00571.x] [PMID]

[22] Ohto U, Ishida H, Krayukhina E, Uchiyama S, Inoue N, Shimizu T. Structure of IZUMO1-JUNO reveals spermoocyte recognition during mammalian fertilization. Nature. 2016; 534(7608):566. [DOI:10.1038/nature18596] [PMID]

[23] Nishimura K, Han L, Bianchi E, Wright GJ, de Sanctis D, Jovine $\mathrm{L}$. The structure of sperm Izumo1 reveals unexpected similarities with Plasmodium invasion proteins. Curr Biol. 2016; 26(14):R661-R2. [DOI:10.1016/j.cub.2016.06.028] [PMID] [PMCID]

[24] Inoue N, Ikawa M, Isotani A, Okabe M. The immunoglobulin superfamily protein Izumo is required for sperm to fuse with eggs. Nature. 2005; 434(7030):234. [DOI:10.1038/nature03362] [PMID]

[25] Takaiso N, Nishizawa H, Nishiyama S, Sawada T, Hosoba E, Ohye T, et al. Mutation analysis of the JUNO gene in female infertility of unknown etiology. Fujita Med J. 2016; 2(3):59-61.

[26] Herrero MB, Mandal A, Digilio LC, Coonrod SA, Maier B, Herr JC. Mouse SLLP1, a sperm lysozyme-like protein involved in sperm-egg binding and fertilization. Dev Biol. 2005; 284(1):126-42. [DOI:10.1016/j.ydbio.2005.05.008] [PMID]

[27] Wagner A, Holland OJ, Tong M, Shelling AN, Chamley LW. The role of SPRASA in female fertility. Reprod Sci. 2015; 22(4):452-61. [DOI:10.1177/1933719114542009] [PMID] [PMCID]

[28] Zhang K, Gao R, Zhang H, Cai X, Shen C, Wu C, et al. Molecular cloning and characterization of three novel lysozymelike genes, predominantly expressed in the male reproductive system of humans, belonging to the c-type lysozyme/ alpha-lactalbumin family. Biol Reprod. 2005; 73(5):1064-71. [DOI:10.1095/biolreprod.105.041889] [PMID]

[29] Li MW, Cherr GN, Yudin AI, Overstreet JW. Biochemical characterization of the $\mathrm{PH}-20$ protein on the plasma membrane and inner acrosomal membrane of cynomolgus macaque spermatozoa. Mol Reprod Dev: Inc Gamete Res. 1997; 48(3):356-66. [DOI:10.1002/(SICI)10982795(199711)48:33.0.CO;2-Q]
[30] Cherr GN, Yudin AI, Overstreet JW. The dual functions of GPI-anchored PH-20: hyaluronidase and intracellular signaling. Matrix Biol. 2001; 20(8):515-25. [DOI:10.1016/S0945053X(01)00171-8]

[31] Primakoff P, Hyatt H, Myles DG. A role for the migrating sperm surface antigen $\mathrm{PH}-20$ in guinea pig sperm binding to the egg zona pellucida. J Cell Biol. 1985; 101(6):2239-44. [DOI:10.1083/jcb.101.6.2239] [PMID] [PMCID]

[32] Lin Y, Mahan K, Lathrop WF, Myles DG, Primakoff P. A hyaluronidase activity of the sperm plasma membrane protein $\mathrm{PH}-20$ enables sperm to penetrate the cumulus cell layer surrounding the egg. J Cell Biol. 1994; 125(5):1157-63. [DOI:10.1083/jcb.125.5.1157] [PMID] [PMCID]

[33] Hunnicutt GR, Primakoff P, Myles DG. Sperm surface protein PH-20 is bifunctional: one activity is a hyaluronidase and a second, distinct activity is required in secondary spermzona binding. Biol Reprod. 1996; 55(1):80-6. [DOI:10.1095/ biolreprod55.1.80] [PMID]

[34] Meyers SA, Yudin AI, Cherr GN, VandeVoort CA, Myles DG, Primakoff $P$, et al. Hyaluronidase activity of macaque sperm assessed by an in vitro cumulus penetration assay. Mol Reprod Dev: Inc Gamete Res. 1997; 46(3):392-400. [DOI:10.1002/(SICI)1098-2795(199703)46:33.0.CO;2-0]

[35] Li M-W, Yudin AI, VandeVoort CA, Sabeur K, Primakoff P, Overstreet JW. Inhibition of monkey sperm hyaluronidase activity and heterologous cumulus penetration by flavonoids. Biol Reprod. 1997; 56(6):1383-9. [DOI:10.1095/biolreprod56.6.1383] [PMID]

[36] Yudin AI, Vandevoort CA, Li MW, Overstreet JW. PH-20 but not acrosin is involved in sperm penetration of the macaque zona pellucida. Mol Reprod Dev: Inc Gamete Res. 1999; 53(3):350-62. [DOI:10.1002/(SICI)10982795(199907)53:33.0.CO;2-9]

[37] Naz RK. Application of sperm antigens in immunocontraception. Front Biosci. 1996; 1:87-95. [DOI:10.2741/A147] [PMID]

[38] Naz R, Menge A. Development of antisperm contraceptive vaccine for humans: why and how? Hum Reprod (Oxford, England). 1990; 5(5):511. [DOI:10.1093/oxfordjournals.humrep.a137134] [PMID]

[39] Naz RK. Involvement of protein tyrosine phosphorylation of human sperm in capacitation/acrosome reaction and zona pellucida binding. Front Biosci. 1996; 1(206):13. [DOI:10.2741/A126] [PMID]

[40] Naz RK, Vanek CM. Testis-specific proteins and their role in contraceptive vaccine development. Front Biosci. 1998; 3:39-48. [DOI:10.2741/A366] [PMID]

[41] Herr JC, Flickinger CJ, Homyk M, Klotz K, John E. Biochemical and Morphological Characterization of the IntraAcrosomal Antigen SP-1O from Human Sperm. Biol Reprod. 1990; 42(1):181-93. [DOI:10.1095/biolreprod42.1.181] [PMID]

[42] Naz RK, Morte C, Garcia-Framis V, Kaplan P, Martinez P. Characterization of a sperm-specific monoclonal antibody and isolation of 95-kilodalton fertilization antigen-2 from human sperm. Biol Reprod .1993; 49(6):1236-44. [DOI:10.1095/ biolreprod49.6.1236] [PMID]

[43] Wheat TE, Goldberg E. Antigenic domains of the spermspecific lactate dehydrogenase C4, isozyme. Mol Immunol. 1985; 22(6):643-9. [DOI:10.1016/0161-5890(85)90093-8] 
[44] Tollner TL, Overstreet J, Branciforte D, Primakoff P. Immunization of female cynomolgus macaques with a synthetic epitope of sperm-specific lactate dehydrogenase results in high antibody titers but does not reduce fertility. Mol Reprod Dev: Inc Gamete Res. 2002; 62(2):257-64. [DOI:10.1002/ mrd.10063] [PMID]

[45] Mohd-Lila M-A, Yee LK, Cen LS, Bala JA, Balakrishnan $\mathrm{KN}$, Allaudin ZN, et al. The application of naked DNA plasmid (DrZP3) and recombinant adenovirus (Ad-rZP3) in rat animal model to determine comparative efficacy of ZP3-Immunocontraceptive vaccines. Microb Pathog. 2019:103572. [DOI:10.1016/j.micpath.2019.103572] [PMID]

[46] Naz R, Packianathan J. Antibodies to human sperm YLP12 peptide that is involved in egg binding inhibit human sperm capacitation/acrosome reaction. Arch Androl. 2000; 45(3):227-32. [DOI:10.1080/01485010050194002] [PMID]

[47] Hao Z, Wolkowicz MJ, Shetty J, Klotz K, Bolling L, Sen B, et al. SAMP32, a testis-specific, isoantigenic sperm acrosomal membrane-associated protein. Biol Reprod. 2002; 66(3):73544. [DOI:10.1095/biolreprod66.3.735] [PMID]

[48] Rao J, Herr JC, Reddi PP, Wolkowicz MJ, Bush LA, Sherman NE, et al. Cloning and characterization of a novel sperm-associated isoantigen (E-3) with defensin-and lectinlike motifs expressed in rat epididymis. Biol Reprod. 2003; 68(1):290-301. [DOI:10.1095/biolreprod.102.005983] [PMID]

[49] Shetty J, Wolkowicz MJ, Digilio LC, Klotz KL, Jayes FL, Diekman AB, et al. SAMP14, a novel, acrosomal membrane-associated, glycosylphosphatidylinositol-anchored member of the Ly-6/urokinase-type plasminogen activator receptor superfamily with a role in sperm-egg interaction. J Biol Chem. 2003; 278(33):30506-15. [DOI:10.1074/jbc. M301713200] [PMID]

[50] Naz RK. Immunocontraceptive effect of Izumo and enhancement by combination vaccination. Mol Reprod Dev. 2008; 75(2):336-44. [DOI:10.1002/mrd.20783] [PMID]

[51] Bijker MS, Melief CJ, Offringa R, Van Der Burg SH. Design and development of synthetic peptide vaccines: past, present and future. Expert Rev Vaccines. 2007; 6(4):591-603. [DOI:10.1586/14760584.6.4.591] [PMID]

[52] Ding X, Li H, Li Y, Huang D, Xiong C. Two B-cell epitope vaccines based on uPA effectively inhibit fertility in male mice. Vaccine. 2018; 36(19):2612-8. [DOI:10.1016/j.vaccine.2018.03.071] [PMID]

[53] Roy A, Kucukural A, Zhang Y. I-TASSER: a unified platform for automated protein structure and function prediction. Nat Protoc. 2010; 5(4):725. [DOI:10.1038/nprot.2010.5] [PMID] [PMCID]

[54] Vita R, Mahajan S, Overton JA, Dhanda SK, Martini S, Cantrell JR, et al. The immune epitope database (IEDB): 2018 update. Nucleic Acids Res. 2018; 47(D1):D339-D43. [DOI:10.1093/nar/gky1006] [PMID] [PMCID]

[55] Jespersen MC, Peters B, Nielsen M, Marcatili P. BepiPred-2.0: improving sequence-based B-cell epitope prediction using conformational epitopes. Nucleic Acids Res. 2017; 45(W1):W24W9. [DOI:10.1093/nar/gkx346] [PMID] [PMCID]

[56] Larsen JEP, Lund O, Nielsen M. Improved method for predicting linear B-cell epitopes. Immunome Res. 2006; 2(1):2. [DOI:10.1186/1745-7580-2-2] [PMID] [PMCID]
[57] Haste Andersen P, Nielsen M, Lund O. Prediction of residues in discontinuous B-cell epitopes using protein 3D structures. Protein Sci. 2006; 15(11):2558-67. [DOI:10.1110/ ps.062405906] [PMID] [PMCID]

[58] Emini EA, Hughes JV, Perlow D, Boger J. Induction of hepatitis A virus-neutralizing antibody by a virus-specific synthetic peptide. J Virol. 1985; 55(3):836-9. [DOI:10.1128/ JVI.55.3.836-839.1985] [PMID] [PMCID]

[59] Kolaskar A, Tongaonkar PC. A semi-empirical method for prediction of antigenic determinants on protein antigens. FEBS Lett. 1990; 276(1-2):172-4. [DOI:10.1016/00145793(90)80535-Q]

[60] Parker J, Guo D, Hodges R. New hydrophilicity scale derived from high-performance liquid chromatography peptide retention data: correlation of predicted surface residues with antigenicity and X-ray-derived accessible sites. Biochem. 1986; 25(19):5425-32. [DOI:10.1021/bi00367a013] [PMID]

[61] Ponomarenko J, Bui H-H, Li W, Fusseder N, Bourne PE, Sette A, et al. ElliPro: a new structure-based tool for the prediction of antibody epitopes. Bmc Bioinform. 2008; 9(1):514 [DOI:10.1186/1471-2105-9-514] [PMID] [PMCID]

[62] Ahmad S, Gromiha M, Fawareh H, Sarai A. ASAView: database and tool for solvent accessibility representation in proteins. BMC Bioinform. 2004; 5(1):51. [DOI:10.1186/14712105-5-51] [PMID] [PMCID]

[63] Reddy Chichili VP, Kumar V, Sivaraman J. Linkers in the structural biology of protein-protein interactions. Protein Sci. 2013; 22(2):153-67. [DOI:10.1002/pro.2206] [PMID] [PMCID]

[64] Chen X, Zaro JL, Shen W-C. Fusion protein linkers: property, design and functionality. Adv Drug Deliv Rev. 2013; 65(10):135769. [DOI:10.1016/j.addr.2012.09.039] [PMID] [PMCID]

[65] Itkonen JM, Urtti A, Bird LE, Sarkhel S. Codon optimization and factorial screening for enhanced soluble expression of human ciliary neurotrophic factor in Escherichia coli. BMC Biotechnol. 2014; 14(1):92. [DOI:10.1186/s12896-014-0092-x] [PMID] [PMCID]

[66] Salsbury FR, Jr. Molecular dynamics simulations of protein dynamics and their relevance to drug discovery. Curr Opin Pharmacol. 2010; 10(6):738-44. [DOI:10.1016/j. coph.2010.09.016] [PMID] [PMCID]

[67] Shamriz S, Ofoghi H. Design, structure prediction and molecular dynamics simulation of a fusion construct containing malaria pre-erythrocytic vaccine candidate, PfCelTOS, and human interleukin 2 as adjuvant. BMC Bioinform. 2016; 17(1):71. [DOI:10.1186/s12859-016-0918-8] [PMID] [PMCID]

[68] Hospital A, Goñi JR, Orozco M, Gelpí JL. Molecular dynamics simulations: advances and applications. Adv Appl Bioinform Chem: AABC. 2015; 8:37. [DOI:10.2147/AABC. S70333] [PMID] [PMCID]

[69] Wiederstein M, Sippl MJ. ProSA-web: interactive web service for the recognition of errors in three-dimensional structures of proteins. Nucleic Acids Res. 2007; 35(Suppl. 2):W407-W10. [DOI:10.1093/nar/gkm290] [PMID] [PMCID]

[70] Laskowski RA, MacArthur MW, Moss DS, Thornton JM. PROCHECK: a program to check the stereochemical quality of protein structures. J Appl Crystallogr. 1993; 26(2):283-91. [DOI:10.1107/S0021889892009944] 
[71] Gasteiger E, Hoogland C, Gattiker A, Wilkins MR, Appel RD, Bairoch A. Protein identification and analysis tools on the ExPASy server. The proteomics protocols handbook: Berlin: Springer; 2005. [DOI:10.1385/1-59259-890-0:571]

[72] Gupta S, Kapoor P, Chaudhary K, Gautam A, Kumar R, Raghava GP, et al. In silico approach for predicting toxicity of peptides and proteins. PloS One. 2013; 8(9):e73957. [DOI:10.1371/journal.pone.0073957] [PMID] [PMCID]

[73] Ivanciuc $\mathrm{O}$, Schein $\mathrm{CH}$, Braun W. SDAP: database and computational tools for allergenic proteins. Nucleic Acids Res. 2003; 31(1):359-62. [DOI:10.1093/nar/gkg010] [PMID] [PMCID]

[74] Saha S, Raghava G. AlgPred: prediction of allergenic proteins and mapping of IgE epitopes. Nucleic Acids Res. 2006; 34(suppl_2):W202-W9. [DOI:10.1093/nar/gkl343] [PMID] [PMCID]

[75] Naz RK. Antisperm Contraceptive Vaccine. Immune Infertility. Berlin: Springer; 2017. [DOI:10.1007/978-3-319-40788-3_17]

[76] Naz RK. Immunization with Sperm Antigens to Induce Contraception. Immune Infertility. Berlin: Springer; 2009. [DOI:10.1007/978-3-642-01379-9_17]

[77] Naz RK. Vaccine for human contraception targeting sperm Izumo protein and YLP12 dodecamer peptide. Protein Sci. 2014; 23(7):857-68. [DOI:10.1002/pro.2476] [PMID] [PMCID]

[78] Kurth BE, Digilio L, Snow P, Bush LA, Wolkowicz M, Shetty $\mathrm{J}$, et al. Immunogenicity of a multi-component recombinant human acrosomal protein vaccine in female Macaca fascicularis. J Reprod Immunol. 2008; 77(2):126-41. [DOI:10.1016/j. jri.2007.06.001] [PMID] [PMCID]

[79] Naz RK. Antisperm contraceptive vaccines: where we are and where we are going? Am J Reprod Immunol. 2011; 66(1):5-12. [DOI:10.1111/j.1600-0897.2011.01000.x] [PMID] [PMCID]

[80] Shrestha A, Wadhwa N, Gupta SK. Evaluation of recombinant fusion protein comprising dog zona pellucida glycoprotein-3 and Izumo and individual fragments as immunogens for contraception. Vaccine. 2014; 32(5):564-71. [DOI:10.1016/j.vaccine.2013.11.078] [PMID]

[81] Barrow PC, Allais L. Developmental toxicity testing of vaccines. Methods Mol Biol (Clifton, NJ). 2013; 947:81-9. [DOI:10.1007/978-1-62703-131-8_7] [PMID] 